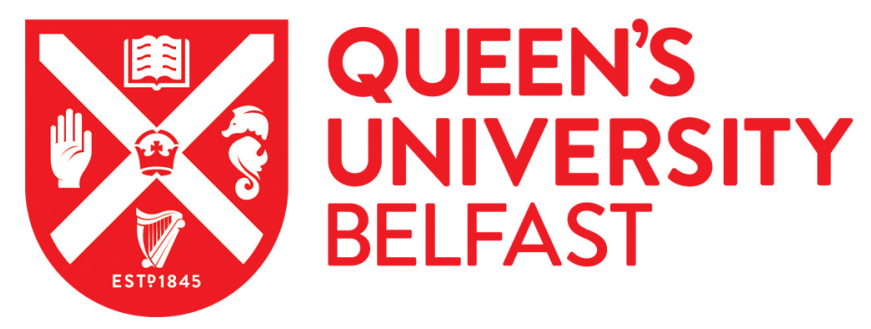

\title{
Assessment and management of constipation for patients receiving palliative care in specialist palliative care settings: a systematic review of the literature
}

Muldrew, D., Hasson, F., Carduff, E., Clarke, M., Coast, J., Finucane, A., Graham, L., Larkin, P., McCorry, N., Slater, P., Watson, M., Wright, E., \& Mcllfatrick, S. (2018). Assessment and management of constipation for patients receiving palliative care in specialist palliative care settings: a systematic review of the literature. Palliative Medicine, 32(5), 930-938. https://doi.org/10.1177/0269216317752515

\section{Published in:}

Palliative Medicine

\section{Document Version:}

Peer reviewed version

Queen's University Belfast - Research Portal:

Link to publication record in Queen's University Belfast Research Portal

\section{Publisher rights}

Copyright 2018 SAGE. This work is made available online in accordance with the publisher's policies. Please refer to any applicable terms of use of the publisher.

\section{General rights}

Copyright for the publications made accessible via the Queen's University Belfast Research Portal is retained by the author(s) and / or other copyright owners and it is a condition of accessing these publications that users recognise and abide by the legal requirements associated with these rights.

Take down policy

The Research Portal is Queen's institutional repository that provides access to Queen's research output. Every effort has been made to ensure that content in the Research Portal does not infringe any person's rights, or applicable UK laws. If you discover content in the

Research Portal that you believe breaches copyright or violates any law, please contact openaccess@qub.ac.uk. 
Assessment and management of constipation for patients receiving palliative care in specialist palliative care settings: a systematic review of the literature.

Dr Deborah HL Muldrew

Ulster University, UK

Dr Felicity Hasson

Ulster University, UK

Dr Emma Carduff

Marie Curie Hospice Glasgow, Glasgow, UK

Professor Mike Clarke

Queens University Belfast, UK

Professor Jo Coast

University of Bristol

Dr Anne Finucane

Marie Curie Hospice Edinburgh, Edinburgh, UK

Dr Lisa Graham

Marie Curie Hospice Belfast, Belfast UK

Professor Philip Larkin

University College Dublin, Dublin, Ireland

Dr Noleen McCorry

Queen's University Belfast, UK

Dr Paul Slater 
Ulster University, UK

Professor Max Watson

Hospice UK

Mrs Eileen Wright

R\&D PPI representative, Belfast, UK

Professor Sonja Mcllfatrick

Ulster University, UK

\section{CORRESPONDING AUTHOR}

Dr Deborah HL Muldrew (née Preshaw)

School of Nursing, Ulster University, Shore Road, Newtownabbey, BT37 OQB

Email: d.preshaw@ulster.ac.uk

Tel: +44 (0) 2890366498 


\section{ABSTRACT}

Background: Constipation is an important issue for patients receiving palliative care within specialist palliative care (SPC) settings. Questions and ambiguity, however, persists about international best practice and management.

Aim: To synthesize the current evidence base on the assessment and management of constipation for palliative care patients within a SPC setting.

Design: Systematic Review

Data Sources: MEDLINE, Embase, Cinahl, Scopus, and Cochrane databases were systematically searched in April 2017 for empirical studies, written in English, on the assessment and management of constipation in SPC settings, published between 2007 and 2017. Two researchers independently reviewed and critically appraised all studies, conducted data extraction and undertook a thematic analysis.

Results: Thirteen studies were included in the review comprising randomised trials $(n=3)$, observational $(n=4)$, and descriptive studies $(n=6)$. Most research was conducted in specialist palliative care units, targeting either healthcare professionals or patients. The analysis highlighted a lack of standard definition of constipation, raising questions on the existence and comparability of baseline prevalence figures, the physical and psychological impact on patients, resource impact on staff and service, the subjective and objective methods of assessing constipation, and key aspects of constipation management, including a lack of focus on non-pharmacological management in this setting.

Conclusions: The results of this review are being used to inform the development of an educational intervention targeting health care professionals. Gaps in the evidence base include lack of consistent definition of constipation, constipation prevention, non-pharmacological management, and the consideration of the management of constipation for the dying patient.

Key Words: constipation, assessment, management, palliative care, patients, hospices, systematic review

\section{KEY STATEMENTS}

What is already known on this topic? 
- Up to $87 \%$ of people will experience symptoms of constipation at some point during their palliative care disease trajectory.

- Constipation causes considerable suffering, either as a direct result of physical symptoms or due to related social and psychological problems such as embarrassment. Despite this, constipation remains poorly recognised and inadequately treated by healthcare providers.

- Uncertainty persists about the "best" management of constipation for palliative care patients.

What this paper adds

- The review demonstrates the lack of standard assessment of constipation for patients in SPC settings at the end of life.

- Clinicians experience challenges in the assessment of constipation and the need to combine patient assessment alongside physical examination and, potentially, the use of radiology

- Clinician response results in an emphasis on pharmacological management, however, consideration around non-pharmacological aspects and impact of dietary and lifestyle factors is also relevant for the management of constipation in this population.

- There is a need to assess current practice for the management of constipation in the dying patient.

What are implications for practice, policy and education?

- The results of this review are being used to inform the development of an educational intervention for the assessment and management of constipation for health professionals.

- Supporting clinicians to more effectively assess and manage the complexities of constipation in this setting is essential in improving overall symptom management for patients at end of life

- National and international policies are necessary within palliative care to ensure best practice guidelines are available and implemented across SPC settings. 


\section{INTRODUCTION}

Palliative care seeks to improve the quality of life and wellbeing of adults and children with a lifelimiting or terminal illness, helping them live as fully as they can for the time they have left (1). A central part of this care includes the management of pain and symptoms (2), seeking to prevent and relieve suffering by early identification and effective assessment and treatment of pain and other problems, physical, psychosocial and spiritual (3).

Constipation is a frequent problem experienced by people with palliative care needs, with overall prevalence rates ranging from $32 \%-87 \%$ in palliative patients (4). This variation may be attributable to the variation in the patient population assessed and the lack of standardised definition of constipation across studies (4). A significant number of people will experience constipation during their palliative care disease trajectory, although, it is noted to be more problematic in advanced disease $(5,6)$. Constipation causes considerable suffering, either as a direct result of physical symptoms or due to related social and psychological problems such as embarrassment (7). Despite this, constipation remains poorly recognised and inadequately treated by healthcare providers. Barriers include lack of understanding, embarrassment, the subjective report from the patient, the lack of an agreed upon definition, a range of assessment tools within clinical practice and limited use of shared diagnostic criteria (such as the Rome III criteria) between healthcare professionals (8). Within the palliative care population, there are multiple factors commonly associated with increased risk of constipation including physical illness, hospitalisation, reduced fluid intake and the use of opioids (4).

Internationally, uncertainty persists about the "best" management of constipation for palliative care patients. Some guidelines do exist globally and at national and regional levels, but the recommendations are varied, both in content and in level of detail. For example, whilst there are European clinical practice recommendations for the management of constipation in palliative care (4), a European Report in Constipation (9) found that, across Europe, fragmented approaches to constipation management existed. France offers clear guidelines for constipation in older adults but not palliative care specific, the Netherlands have guidelines for general practitioners but without a focus on older adults, and the Czech Republic, Italy, and Germany have no standards or guidelines for constipation. This raises the issue with the various guidelines of the lack of specific information for palliative care patients, therefore, the lack of transferability to palliative settings. Other examples include the Australian Guidelines for constipation in children (10), Australian guidelines for antenatal constipation (11), and global guidelines for all adult patients (12). Cultural differences also need to be considered in relation to the guidelines. For example, researchers in Asia (13) reported constipation to differ between Asia and Western countries due to differences in patient perception and self-management, dietary practices, intestinal physiology, and healthcare infrastructure.

While constipation is an important issue for palliative care patients and prevalence is variable, uncertainty still persists in clinical practice regarding the assessment and management of constipation in SPC settings.

\section{$\underline{\text { Aim }}$}

To synthesize the current evidence base on the assessment and management of constipation for palliative care patients in a SPC setting.

\section{METHODS}

A systematic review was undertaken utilising Aveyard's (14) guide to undertaking a literature review in health and social care and the PRISMA Checklist (15). This approach was chosen to address a 
defined research aim using empirical evidence within a pre-specified set of eligibility criteria. A range of search techniques were used including electronic database searching, reference list checking, contacting experts, and citation searching (16).

\section{Search Strategy}

Studies were identified in April 2017 by systematic database searches in conjunction with a subject Librarian, scanning reference lists of included articles, and consultation with the project's Steering Group (clinical and academic experts in constipation and hospice care). We reviewed MEDLINE, CINAHL plus, Embase, Scopus, and Cochrane Central Register of Controlled Trials (Appendix 2). Key search Terms included: Palliative care OR Terminal care OR Hospice care OR End of Life; Constipation OR Constipat*; Hospice* OR Palliative care unit; and Manag* OR Assess* OR Symptom management. Only articles published after 1 January 2007 were included, given that the key paper on constipation in palliative care was published in 2008 (4).

Table 1: Inclusion criteria for the selection of articles

Inclusion Criteria

1. Empirical Research

2. Constipation assessment or management as a primary theme or focus

3. Focus on palliative and end of life care

4. Study was conducted in a hospice or specialist palliative care (SPC) unit

5. 2007-2017 publication date

6. Published in English

\section{Search Outcome}

The initial search retrieved 135 articles across all databases, with 103 articles remaining following the removal of duplicates. Title and abstract screening against the inclusion criteria was completed independently by two reviewers (DP and FH) and following the removal of irrelevant articles 15 articles remained. The full texts of these articles were retrieved and independently assessed for relevance. Four articles were excluded for the following reasons: not empirical (1); and the research was conducted outside a hospice setting (3). Two additional articles were identified through reference list screening. Thirteen articles were included in the final review (Appendix 1).

Quality appraisal was undertaken using the Joanna Briggs Institute (JBI) levels of evidence (the Joanna Briggs Institute 2014). These include five levels of evidence: experimental; quasiexperimental; observational analytic; observational descriptive; and expert opinion/bench research. At all stages of the process the articles were individually assessed, reviewed and appraised by two members of the research team (DP and FH), and any disagreements were mediated by a third reviewer (SM).

\section{Data Extraction and Synthesis}

Data were extracted using an adapted data extraction form based on the work of Taylor (17). This was piloted and refined as required. Data extraction detailed; study details; location; aims and objectives; sample, methods, data analysis, the aspect of constipation assessment, management, or treatment discussed, and main findings (See Supplementary File). Two authors independently reviewed the included articles to thematically synthesize the key aspects of constipation assessment and management. Thematic synthesis included line by line coding of the findings of the primary 
studies, the categorisation of codes into the descriptive themes of assessment and management, and the development of analytical themes within the descriptive categories (18).

Table 2: Contribution of papers to Themes

\begin{tabular}{|l|c|c|c|c|c|c|c|c|c|c|c|c|c|}
\hline Theme & 1 & 2 & 3 & 4 & 5 & 6 & 7 & 8 & 9 & 10 & 11 & 12 & 13 \\
\hline Assessment & $\mathrm{X}$ & $\mathrm{X}$ & $\mathrm{X}$ & $\mathrm{X}$ & & $\mathrm{X}$ & & $\mathrm{X}$ & $\mathrm{X}$ & & & & \\
\hline Management & $\mathrm{X}$ & $\mathrm{X}$ & & & $\mathrm{X}$ & & $\mathrm{X}$ & & & $\mathrm{X}$ & $\mathrm{X}$ & $\mathrm{X}$ & $\mathrm{X}$ \\
\hline
\end{tabular}

1. Cheng (2013)

2. Clarke (2011)

3. Downing (2007)

4. Hawley (2011)

5. Laugsand (2009)

6. Nagaviroj (2011)

7. Slatkin (2009)

8. Strassels (2010)

9. Tai (2016)

10. Tarumi (2013)

11. Tavares (2014)

12. Thomas (2008)

13. Wee 2010 


\section{RESULTS}

\section{Characteristics of included articles}

The designs of the included studies were three randomised trials (19-21), four observational designs (22-25), and six descriptive designs (26-31). Drawing on the Joanna Briggs Institutes' Levels of evidence for effectiveness, two articles were ranked at level one, six at level three, and five at level four, showing a broad range of evidence within the review.

Four of the studies were conducted in Canada $(20,23,27,28)$, four in the USA $(19,21,24,29)$, and one study was conducted in each of Australia (22), China (26), Norway (31), Taiwan (25), and the UK (30). Specialist palliative care (SPC) units within medical centres $(26)$, hospitals $(23,27,28)$, and teaching hospitals $(22,25)$ were the most common locations of research. A SPC unit was referred to in three studies $(19,27,30)$, and a mixture of various hospice care settings were referred to in three further studies $(24,29,31)$.

The focus of the studies ranged vastly across studies. The history of constipation and its links to clinical and demographic characteristics was examined by Strassels et al (24). Bowel habits and their associated factors were also considered by Cheng and colleagues (26). Four studies focused on constipation treatments including docusate (20), Methylnaltrexone $(19,21)$, and Oral preparation of Petroleum Jelly (OPJ) (29). Another study examined the relationship between laxatives and bowel movement frequency (22). Bowel assessment scales including the Victoria Bowel Performance Scale $(23,27)$ and the Constipation Assessment Scale $(28)$ were analysed in three studies. Palliative care outcomes including symptom prevalence or severity $(25,31)$, were the focus of two studies, both of which identified constipation as a key symptom or outcome within the abstract. Finally, one study considered the financial cost of managing constipation in patients taking opioids (30).

Three studies recruited patient with advanced cancer $(25,26,28)$, one of which specified they must also be on medication for bowel movement (26). Five further studies included inpatients who either were prescribed laxatives (22), had constipation scores recorded $(24)$, or were on opioids $(19,21,30)$. Three studies included all inpatients (20), or inpatients and outpatients $(27,31)$, irrespective of diagnosis or report of constipation. Three studies included healthcare providers including staff nurses (23), and a mixture of nursing, medical, and pharmacy staff (27) (29) nursing, pharmacy, and medical staff.

\section{Synthesized thematic findings}

\section{Constipation Assessment}

Constipation was identified as one of the most common symptoms, particularly in the case of patients with GI tract cancers, through the assessment of symptom severity in Tai's study (25). The frequency of constipation was supported by a retrospective cohort study across the United States which found constipation was assessed an average of four times per person admitted to hospice care (24). Methods of assessment of constipation varied considerably for those studies whose primary goal focused on assessment. Two studies used a variety of constipation specific tools and criteria which are well known, such as the Bristol Stool Chart, Constipation Visual Analogue Scale, and Rome II diagnostic criteria $(20,26)$. Two studies used accepted cut off points for diagnosing constipation without referencing the specific criteria, for example, number of bowel movements, and bowel function $(19,22)$. The importance of including the patient's subjective experience of constipation alongside other objective measures was identified in one study as an important element of assessment (26). Only one study reported the use of rectal examinations, which were done in 24 of 70 admissions over a six month period in a SPC unit (30). 
Non standardised tools including a constipation intensity numeric rating scale (24) were also identified as a key component of constipation assessment. Others tools were used which assessed a broader concept, but which identified constipation as one of the components for example, the Palliative Performance Scale (PPS), and a Symptom severity reporting form $(20,25)$.

Three studies had a primary focus on constipation assessment tools including the Victoria Bowel Performance Scale (BPS) $(23,27)$, and the Constipation Assessment Scale (28). The Victoria BPS is a bipolar, nine-point ordinal scale which ranges from +4 (diarrhoea) to -4 (constipation) which considers stool frequency, consistency, and patient ability to control evacuation. Eighteen test cases were developed by Downing et al (23), which showed good inter and intra rater reliability. The small number of confounding test cases illustrated the need to understand the instructions for the BPS, but overall it was found to be quick, easy, and reliable. Hawley and colleagues (27) supported these findings, reporting the tool as an acceptable and useful bowel function assessment tool. Interestingly, the tool was modified to remove the reference to the three-day interval between bowel movements, swapping it for the patient's desired goal for how often they want to have a bowel movement. Nagaviroj et al (28) compared the patients' scores on the Constipation Assessment Scale with the physicians' interpretations of a plain abdominal radiograph. The findings suggested no correlation between the two different instruments, concluding that objective and subjective assessments could not be considered gold standard when used alone, but rather, should be used in conjunction with one another.

\section{Constipation Management}

Three studies focused on specific medication including docusate (20), methylnaltrexone for opioid induced constipation (19), and Oral Preparation of Petroleum Jelly (OPJ) (29). A further study examined the relationship between laxatives and bowel movement frequency (22), and Cheng et al (26) aimed to evaluate laxative use in advanced cancer patients within a SPC unit.

In Cheng's (26) study, 92\% of 225 SPC unit patients were on at least one of the following interventions: laxatives, suppositories, enemas, digital evacuation, "over the counter" medications, Chinese herbal medicine (CHM) or health supplements. It was found that 147 (65.3\%) of the patients were on laxatives prescribed by SPC unit doctors. The use of laxatives, enemas, suppositories, digital evacuation and "over the counter" medications did not significantly differ, however, the proportion of patients receiving $\mathrm{CHM}$ or health supplements for constipation was significantly higher in the no constipation group than the constipation and severe constipation group. Laugsand (31) found Senna to be the most commonly prescribed laxative in Switzerland (54\%), but, Lactulose was used by $52 \%$ in Sweden, $51 \%$ in Portugal, 56\% in Denmark, $60 \%$ in the Netherlands, and $100 \%$ in Luxemburg. However, despite $18 \%$ of SPC unit patients reporting moderate or severe constipation, approximately a third were not given any drugs for symptom management. In a study of 211 admissions to a SPC unit in Australia (22), Docusate with Senna was the most commonly prescribed combination of laxatives $(n=119)$, followed by Docusate with Senna and Macrogol $(n=86)$. However, this study found no relationship between the prescription of laxatives and the frequency of documented bowel movements. The authors suggest that this may be caused by a limited number of attempts within palliative care to objectively explore the functional problems of the colon and pelvis which may contribute to constipation. Alternatively, they reported that laxatives were prescribed based on subjective patients' reports.

To assess the efficacy of Docusate, Tarumi et al (20) conducted a randomised, double-blind, placebo controlled trial of oral docusate in 74 adult hospice patients ( $75 \%$ completed the study). There were no significant differences between the treatment groups in stool frequency, volume, consistency, 
difficulty or completeness of evacuation, or on the Edmonton Symptom Assessment Scale scores between the groups. Rescue laxatives were needed for many participants, with interventions including bisacodyl suppository, sodium phosphate enema, and lactulose. It was concluded that there was no significant benefit of adding Docusate to Sennoside, but this may have been attributable to the use of co-interventions including additional laxatives and bowel interventions as required. In addition, the patients were terminally ill with various superimposed conditions which may have resulted in different responses or not responding to Docusate treatment.

As a third line therapy after oral laxatives and suppositories, Tavares (29) found OPJ produced a bowel movement within 24 hours in $88 \%(n=117)$ of cases, with low adverse effects reported. In this study, $67 \%(n=237)$ of healthcare practitioners were familiar with the use of OPJ, however, there was a lack of consistency in the amount of OPJ recommended, from one to four balls per dose at varying intervals. In this study, $72 \%(n=106)$ of surveyed healthcare professionals who currently recommend OPJ would recommend their use in cases of high impaction. While high impaction and hard stools in the rectum were the most likely situations in which OPJ was used, it was not limited to this scenario.

When considering pharmacological management, the role of opioids as a cause of constipation has been identified across multiple studies. Cheng et al. (26) found $60.9 \%(n=137)$ patients were prescribed opioids, and prophylactic prescriptions of laxatives were recommended. Patients not on opioids as compared to patients on strong opioids had similar CVAs scores and description of constipation but had the least laxatives prescribed. The proportion of patients on strong opioids was significantly higher in the severe constipation group (34.3\%) than the no constipation group (13.6\%) and constipation group (24.6\%) [p=0.048]. Patients on strong, as compared to weak and no opioids, were significantly younger, had more laxatives prescribed $(\mathrm{p}<0.001)$, and had less prevalence of hard stools. There were no differences in mean CVAS score and their description of constipation symptoms. Patients not on opioids were prescribed with least laxatives, and a higher proportion of them were on "over the counter" medications $(28.4 \%)$ as compared with patients on weak and strong opioids (6.3 and $8.8 \%$, respectively, $p<0.001)$. (26).

Thomas et al (21) used a double-blind, randomized, placebo-controlled trial to assess the efficacy of Methylnaltrexone in treating opioid induced constipation (OIC). Out of 133 patients enrolled in the trial, $48 \%$ of the Methylnaltrexone group (receiving $0.15 \mathrm{mg} / \mathrm{kg}$ body weight) had laxation within four hours, compared to $15 \%$ of the placebo group $(P<0.001)$. The median time to laxation was significantly shorter in the Methylnaltrexone group; but abdominal pain and flatulence were reported as adverse events. These findings were further supported by Slatkin et al (19) who explored the efficacy of Methylnaltrexone in the treatment of OIC in 154 patients (80\% with a cancer diagnosis). In this multicentre, single dose, double blind, randomised placebo-controlled trial, three treatment groups were created at a 1:1:1 ratio. One group received $0.15 \mathrm{mg} / \mathrm{kg}$ of Methylnaltrexone, a second group received $0.3 \mathrm{mg} / \mathrm{kg}$ of Methylnaltrexone, and the third group received a placebo. The proportion of people who defecated within four hours of receiving $0.15 \mathrm{mg} / \mathrm{kg}, 0.3 \mathrm{mg} / \mathrm{kg}$, and placebo was $67 \%$ (95\% Cl: $47.8 \%-75.6 \%), 58.2 \%$ (45.1\%-71.2\%), and 13.5\% (4.2\%-22.7\%) ( $p<0.0001$ for each Methylnaltrexone dose vs placebo), respectively. During the double blind phase, approximately half of the patients who defecated reported improvement in stool consistency irrespective of treatment. Administration of Methylnaltrexone did not impact on baseline pain, and use of Methylnaltrexone did not result in opioid withdrawal. The proportion of patients who reported any improvement in constipation distress at the four-hour assessment was $64.4 \%, 63.5 \%$ and $34 \%$ for $0.15 \mathrm{mg} / \mathrm{kg}, 0.3 \mathrm{mg} / \mathrm{kg}$, and placebo groups, respectively. Common adverse events 
included mild-moderate pain, flatulence, nausea, and dizziness, and were directly linked to Methylnaltrexone.

The financial cost of constipation management was address in one study (30). This study found the most time consuming activity was staff discussion about bowel management, which occurred at least once daily for doctors and twice daily for nurses, and involved up to eight members of staff per discussion. In 50 of 70 admissions in the study, the estimated direct costs relating to the management of constipation was $f 30$ or less, whereas in four admissions, the cost incurred exceeded $f 100$ each. The direct cost of managing constipation was estimated at a mean cost per admission of $f 29.81$ (95\% confidence interval $[\mathrm{Cl}] £ 21.36-f 38.26)$. By contrast, the mean cost of opioid medications per admission was $£ 43.21$ (95\% Cl £21.81- $€ 64.60)$.

\section{DISCUSSION}

The purpose of this review was to synthesize the current evidence base on the assessment and management of constipation for palliative care patients within SPC settings. Using a systematic approach, fourteen international studies were identified which focused on constipation within the SPC setting from the last decade of research. The synthesis of studies demonstrated a lack of standardised assessment which combined the patient's subjective assessment with an objective physical examination. There was a lack of focus on non-pharmacological management, such as considering dietary and lifestyle factors for this population. Additionally, there was a lack of guidance and consideration of constipation management for the dying patient.

\section{Main findings}

In terms of assessment and diagnosing constipation, Clark et al. (22) found little relationship between laxative prescribing patterns and frequency of bowel movements, attributable to the limited attempts in palliative care to objectively explore functional problems of the colon. This is supported by the findings of Nagaviroj (28) who found no correlation between the subjective and objective measures of constipation. The limited predictive value of subjective scales for constipation including verbal numerical scales have also been found in other palliative settings, for example, in the hospital and in community settings (32). While it is important to document a detailed and accurate patient history, and receive subjective perceptions of bowel function, the literature suggests that this must be balanced with objective measurement. This supports the revision to the BPS (27) which changed one of the criteria from three days to the patient's goal for bowel movement frequency. These studies paint a picture of the need for subjective assessment of constipation, and the importance of taking a detailed history. While the patient's assessment is essential, this should be combined with a physical examination from a qualified healthcare professional, the use of a digital rectal examination where necessary, and potentially the use of radiology to out rule malignant intestinal obstruction (33-35). Additionally, the wide variety of tools identified through the findings on assessment draws attention to the need to develop shared tools between healthcare professionals to improve consistency of diagnosis.

The primary focus of constipation management across the studies was pharmacological approaches, including docusate, Methylnaltrexone, and OPJ (19-21,29). Given the high prevalence of pain and, therefore, opioid use, in this population it is not surprising that opioid induced constipation (OIC) is common. Methylnaltrexone was found to be effective within the hospice setting in treating OIC, further supported by the national guidelines on constipation (34). However, the findings of this review are inconclusive regarding the most effective pharmacological treatment of constipation. This is supported by the systematic review by Candy on the effectiveness of laxatives, which found 
limited evidence to support the use of one laxative over another (36). Instead, it was suggested that the choice be made based on patient preference and circumstance, followed by cost effectiveness when no clear patient preference was evident (34). A key finding of Laugsand (31) was that a third of patients with moderate to severe constipation were not offered any drug treatment, highlighting the need to ensure all symptoms are addressed without focusing on one prominent symptom.

When considering the relationship between frequency of bowel movements and laxatives, it was noteworthy that there was no discussion focusing on the impact of non-pharmacological measures (22). This was a similar trend across all studies, none of which raised any methods of nonpharmacological management for constipation despite an recommendation within recent clinical guidelines that this aspect should be considered equally important to pharmacological management (34). Furthermore, aroma massage has been used in advanced cancer patients in Chinese oncology wards to improve bowel movements and quality of life (37). This highlights the need for future research to include assessment and implementation of non-pharmacological alongside a pharmacological approach to constipation and to explore the impact of dietary and lifestyle factors in constipation management.

The National Clinical Effectiveness Committee guidelines (34) suggested that rectal intervention is rarely used in the last stage of illness. Constipation management becomes a lower priority, and as consciousness levels deteriorate oral laxatives should be discontinued. However, the correct timing for the cessation of laxatives in the approach to death remains unclear (38). The reduced priority of constipation in the dying patient is evident in the literature, with no studies reporting any form of constipation assessment, management, or intervention during the last days of life. However, this gap in the literature could be addressed in future research by assessing and addressing what happens in current practice, given the changing priorities in the management of patient care in their last days of life and how this should be approached by healthcare providers.

\section{Strengths and limitations}

This review has taken an important area of symptom management in palliative care and focused specifically on the SPC setting, making the findings directly relevant to this clinical area. Whilst all attempts were made to be inclusive of all SPC units within medical centres, palliative care centres, and hospice buildings, this cannot be verified based on the available evidence. Similarly, with the many definitions of constipation, and the potential range of phrases such as "bowel movements," only those articles with constipation in the title, abstract, or key words were included in the review. This is acknowledged as a limitation. Additionally, the aims of the review had to be kept broad to ensure nothing was missed which may capture an aspect of constipation assessment or management, however, this made it impossible to undertake additional analysis beyond a thematic synthesis. The authors further acknowledge limitations when considering palliative care patients recognising that they comprise a heterogeneous group in terms of diagnosis and function.

\section{What this study adds}

A synthesis of the key developments surrounding constipation assessment and management in SPC settings over the last decade has been presented in this review. Key areas, which have been addressed, include the variety of methods to assess constipation, and the methods of pharmacological management for constipation. Gaps for future research including the need for a clearer definition of constipation, constipation prevention, non-pharmacological management, and management of constipation for the dying patient have been identified. The results of this review are being used to inform the development of an educational intervention targeting healthcare professionals. The intervention aims to bring together healthcare professionals, to not only provide 
educational content on the assessment and management of constipation and key challenges, but also assist them in engaging in real work interaction patient care learning. It is anticipated that such an approach will improve the future assessment and management of this difficult symptom for palliative care patients.

\section{DECLARATIONS}

Authorship: All authors contributed to the conception and design of this work, acquisition, analysis, and interpretation of data, or drafting and revising it critically for intellectual content.

Acknowledgements: We would like to acknowledge the assistance of Dr Kathy Armour in the design and development of the wider research project.

Declaration of conflicting interests: The authors declare no potential conflicts of interest with respect to the research, authorship and/or publication of this article

Funding: This research was funded by a research grant awarded to Professor Sonja Mcllfatrick by Marie Curie UK (REF MCCC-RP-16-A20993). 


\section{REFERENCES}

1. Hospice UK. What is Hospice Care? [Internet]. 2017 [cited 2017 Mar 23]. Available from: https://www.hospiceuk.org/about-hospice-care/what-is-hospice-care

2. McMillan SC. Presence and severity of constipation in hospice patients with advanced cancer. AmJHospPalliatCare. 2002;19(1049-9091 (Print)):426-30.

3. World Health Organization. WHO Definition of Palliative Care [Internet]. 2017 [cited 2017 Mar 14]. Available from: http://www.who.int/cancer/palliative/definition/en/

4. Larkin PJ, Sykes NP, Centeno C, Ellershaw JE, Elsner F, Eugene B, et al. The management of constipation in palliative care: clinical practice recommendations. Palliat Med. 2008;22(7):796-807.

5. Clark K, Smith JM, Currow DC. The Prevalence of Bowel Problems Reported in a Palliative Care Population. J Pain Symptom Manage [Internet]. 2012 [cited 2017 Apr 11];43(6):993-1000. Available from: http://www.sciencedirect.com/science/article/pii/\$0885392412000954

6. Fallon MT. Constipation in cancer patients: Prevalence, pathogenesis, and cost-related issues. Eur J Pain [Internet]. 1999 Dec [cited 2016 Dec 2];3(S1):3-7. Available from: http://doi.wiley.com/10.1016/S1090-3801\%2899\%2990169-6

7. Andrews A, Morgan G. Constipation management in palliative care: treatments and the potential of independent nurse prescribing. Int J Palliat Nurs [Internet]. 2012 Jan [cited 2016 Oct 7];18(1):17-22. Available from: http://www.magonlinelibrary.com/doi/abs/10.12968/ijpn.2012.18.1.17

8. Doyle D, Hanks GW., Cherny N, Calmnan K. Constipation and Diarrhoea. In: Oxford textbook of palliative medicine. Oxford: UK: Oxford University Press; 2004. p. 483-96.

9. International Longevity Centre UK. The Burden of Constipation in our Ageing Population: Working Towards Better Solutions. Brussels; 2013.

10. Department of Health Government of South Australia. South Australian Paediatric Practice Guidelines: Constipation in Children. SA Child Health Clinical Network; 2014.

11. Department of Health. Clinical Practice Guidelines Antenatal Care: Constipation [Internet]. 2013. Available from:

http://www.health.gov.au/internet/publications/publishing.nsf/Content/clinical-practiceguidelines-ac-mod1 $\sim$ part-b $\sim$ clinical-assessments $+\sim$ constipation

12. World Gastroenterology Organisation. Constipation: A Global Perspective [Internet]. Global Guidelines. 2010 [cited 2017 Apr 10]. Available from: http://www.worldgastroenterology.org/guidelines/globalguidelines/constipation/constipation-english

13. Gwee K-A, Ghoshal UC, Gonlachanvit S, Chua ASB, Myung S-J, Rajindrajith S, et al. Primary Care Management of Chronic Constipation in Asia: The ANMA Chronic Constipation Tool. J Neurogastroenterol Motil [Internet]. 2013 Apr [cited 2017 Apr 10];19(2):149-60. Available from: http://www.ncbi.nlm.nih.gov/pubmed/23667746

14. Aveyard H. Doing a literature review in health and social care : a practical guide. Doing A Literature Review In Health And Social Care : A Practical Guide. 2014.

15. Liberati A, Altman DG, Tetzlaff J, Mulrow C, Gøtzsche PC, loannidis JPA, et al. The PRISMA Statement for Reporting Systematic Reviews and Meta-Analyses of Studies That Evaluate Health Care Interventions: Explanation and Elaboration. PLoS Med [Internet]. 2009 Jul 21 
[cited 2017 Mar 31];6(7):e1000100. Available from:

http://www.ncbi.nlm.nih.gov/pubmed/19621070

16. Papaioannou D, Sutton A, Carroll C, Booth A, Wong R. Literature searching for social science systematic reviews: Consideration of a range of search techniques. Health Info Libr J. 2010;

17. Taylor BJ, Campbell K, McGlade A. Understanding and Using Research in Social Work. Wharton K, editor. Thousand Oaks CA: Sage Publications Inc; 2015.

18. Thomas J, Harden A. Methods for the thematic synthesis of qualitative research in systematic reviews. BMC Med Res Methodol [Internet]. 2008 Dec 10 [cited 2017 Nov 2];8(1):45. Available from: http://bmcmedresmethodol.biomedcentral.com/articles/10.1186/14712288-8-45

19. Slatkin N, Thomas J, Lipman AG, Wilson G, Boatwright ML, Wellman C, et al. Methylnaltrexone for treatment of opioid-induced constipation in advanced illness patients. J Support Oncol [Internet]. 2009 [cited 2017 Mar 23];7(1):39-46. Available from: http://www.ncbi.nlm.nih.gov/pubmed/19278178

20. Tarumi Y, Wilson MP, Szafran O, Spooner GR. Randomized, double-blind, placebo-controlled trial of oral docusate in the management of constipation in hospice patients. J Pain Symptom Manage. 2013;45(1):2-13.

21. Thomas J, Karver S, Cooney GA, Chamberlain BH, Watt CK, Slatkin NE, et al. Methylnaltrexone for Opioid-Induced Constipation in Advanced Illness. N Engl J Med [Internet]. 2008 [cited 2017 Mar 31];359(10):1070-1. Available from: http://www.nejm.org/doi/pdf/10.1056/NEJMoa0707377

22. Clark K, Lam L, Currow D. Exploring the relationship between the frequency of documented bowel movements and prescribed laxatives in hospitalized palliative care patients. Am J Hosp Palliat Care [Internet]. 2011 Jun 1 [cited 2017 Mar 23];28(4):258-63. Available from: http://ajh.sagepub.com/cgi/doi/10.1177/1049909110385548

23. Downing GM, Kuziemsky C, Lesperance M, Lau F, Syme A. Development and Reliability Testing of the Victoria Bowel Performance Scale (BPS). J Pain Symptom Manage [Internet]. 2007 Nov [cited 2017 Mar 23];34(5):513-22. Available from: http://linkinghub.elsevier.com/retrieve/pii/S0885392407004150

24. Strassels SA, Maxwell TL, lyer S. Constipation in persons receiving hospice care. J Pain Symptom Manage [Internet]. 2010 Dec [cited 2017 Mar 23];40(6):810-20. Available from: http://linkinghub.elsevier.com/retrieve/pii/S0885392410005166

25. Tai S-Y, Lee C-Y, Wu C-Y, Hsieh H-Y, Huang J-J, Huang C-T, et al. Symptom severity of patients with advanced cancer in palliative care unit: longitudinal assessments of symptoms improvement. BMC Palliat Care [Internet]. 2016 Dec 11 [cited 2017 Mar 23];15(1):32. Available from: http://www.biomedcentral.com/1472-684X/15/32

26. Cheng CW, Kwok AOL, Bian ZX, Tse DMW. A cross-sectional study of constipation and laxative use in advanced cancer patients: Insights for revision of current practice. Support Care Cancer. 2013;21(1):149-56.

27. Hawley P, Barwich D, Kirk L. Implementation of the victoria bowel performance scale. J Pain Symptom Manage [Internet]. 2011 Dec [cited 2017 Mar 23];42(6):946-53. Available from: http://www.ncbi.nlm.nih.gov/pubmed/21620645

28. Nagaviroj K, Yong WC, Fassbender K, Zhu G, Oneschuk D. Comparison of the constipation assessment scale and plain abdominal radiography in the assessment of constipation in 
advanced cancer patients. J Pain Symptom Manage [Internet]. 2011 Aug [cited 2017 Mar 23];42(2):222-8. Available from:

http://linkinghub.elsevier.com/retrieve/pii/S0885392411000637

29. Tavares CN, Kimbrel JM, Protus BM, Grauer PA. Petroleum Jelly (Vaseline Balls) for the Treatment of Constipation: A Survey of Hospice and Palliative Care Practitioners. Am J Hosp Palliat Med [Internet]. 2014 Dec 1 [cited 2017 Mar 23];31(8):797-803. Available from: http://ajh.sagepub.com/cgi/doi/10.1177/1049909113502578

30. Wee B, Adams A, Thompson K, Percival F, Burslem K, Jobanputra M. How Much Does It Cost a Specialist Palliative Care Unit to Manage Constipation in Patients Receiving Opioid Therapy? J Pain Symptom Manage [Internet]. 2010 Apr [cited 2017 Mar 23];39(4):644-54. Available from: http://linkinghub.elsevier.com/retrieve/pii/S0885392410000801

31. Laugsand EA, Kaasa S, de Conno F, Hanks G, Klepstad P, Research Steering Committee of the EAPC. Intensity and treatment of symptoms in 3,030 palliative care patients: a cross-sectional survey of the EAPC Research Network. J Opioid Manag [Internet]. [cited 2017 May 4];5(1):1121. Available from: http://www.ncbi.nlm.nih.gov/pubmed/19344044

32. Noguera A, Centeno C, Librada S, Nabal M. Screening for constipation in palliative care patients. J Palliat Med [Internet]. 2009 Oct [cited 2017 Apr 10];12(10):915-20. Available from: http://www.liebertonline.com/doi/abs/10.1089/jpm.2009.0054

33. Clark K, Lam LT, Talley NJ, Quinn J, Blight A, Byfieldt N, et al. Assessing the Presence and Severity of Constipation with Plain Radiographs in Constipated Palliative Care Patients. J Palliat Med [Internet]. 2016 [cited 2017 Apr 10];19(6):jpm.2015.0451. Available from: http://online.liebertpub.com/doi/pdf/10.1089/jpm.2015.0451

34. National Clinical Effectiveness Committee. Management of Constipation in Adult Patients Receiving Palliative Care National Clinical Guideline No . 10 November 2015. 2015.

35. Noble S. Other problems in palliative care. Medicine (Baltimore) [Internet]. 2011 Nov [cited 2017 Mar 23];39(11):668-73. Available from:

http://linkinghub.elsevier.com/retrieve/pii/S1357303911002222

36. Candy B, Jones L, Larkin PJ, Vickerstaff V, Tookman A, Stone P. Laxatives for the management of constipation in people receiving palliative care. In: Candy B, editor. Cochrane Database of Systematic Reviews [Internet]. Chichester, UK: John Wiley \& Sons, Ltd; 2015 [cited 2016 Nov 4]. Available from: http://doi.wiley.com/10.1002/14651858.CD003448.pub4

37. Lai TKT, Cheung MC, Lo CK, Ng KL, Fung YH, Tong M, et al. Effectiveness of aroma massage on advanced cancer patients with constipation: a pilot study. Complement Ther Clin Pract [Internet]. 2011 Feb [cited 2017 Apr 7];17(1):37-43. Available from: http://linkinghub.elsevier.com/retrieve/pii/S1744388110000113

38. Clark K, Hipwell A, Byfieldt N. A retrospective pilot study to explore the timing of cessation of laxatives before death in a palliative care unit. Int J Palliat Nurs [Internet]. 2012 [cited 2017 Apr 10];18(7):326-30. Available from: http://www.magonlinelibrary.com/doi/pdf/10.12968/ijpn.2012.18.7.326 
Appendix 1: Search Strategy

CINAHL

\begin{tabular}{|l|l|l|}
\hline$\#$ & Searches & Results \\
\hline 1 & MH ("Palliative Care") & 25628 \\
\hline 2 & MH ("Terminal Care") & 48498 \\
\hline 3 & MH ("Hospice Care") & 7014 \\
\hline 4 & palliative or terminal* or hospice or end of life & 68844 \\
\hline 5 & (MH “Constipation") & 4299 \\
\hline 6 & "Constipat*” & 6508 \\
\hline 7 & (MH “Hospices") & 2782 \\
\hline 8 & ("hospice*) & 15763 \\
\hline 9 & ("palliative care unit") & 571 \\
\hline 10 & Manag* or Assess* or (symptom* N5 manag*) & 976558 \\
\hline 11 & S1 OR S2 OR S3 OR S4 & 75037 \\
\hline 12 & S5 or S6 & 6508 \\
\hline 13 & S7 OR S8 or S9 & 16204 \\
\hline 14 & S10 AND S11 AND S12 AND S13 (Limiters - Publication Year: 2007-2017, English & 23 \\
& Language, Research article) & \\
\hline
\end{tabular}


Appendix 2: PRISMA Flow Chart
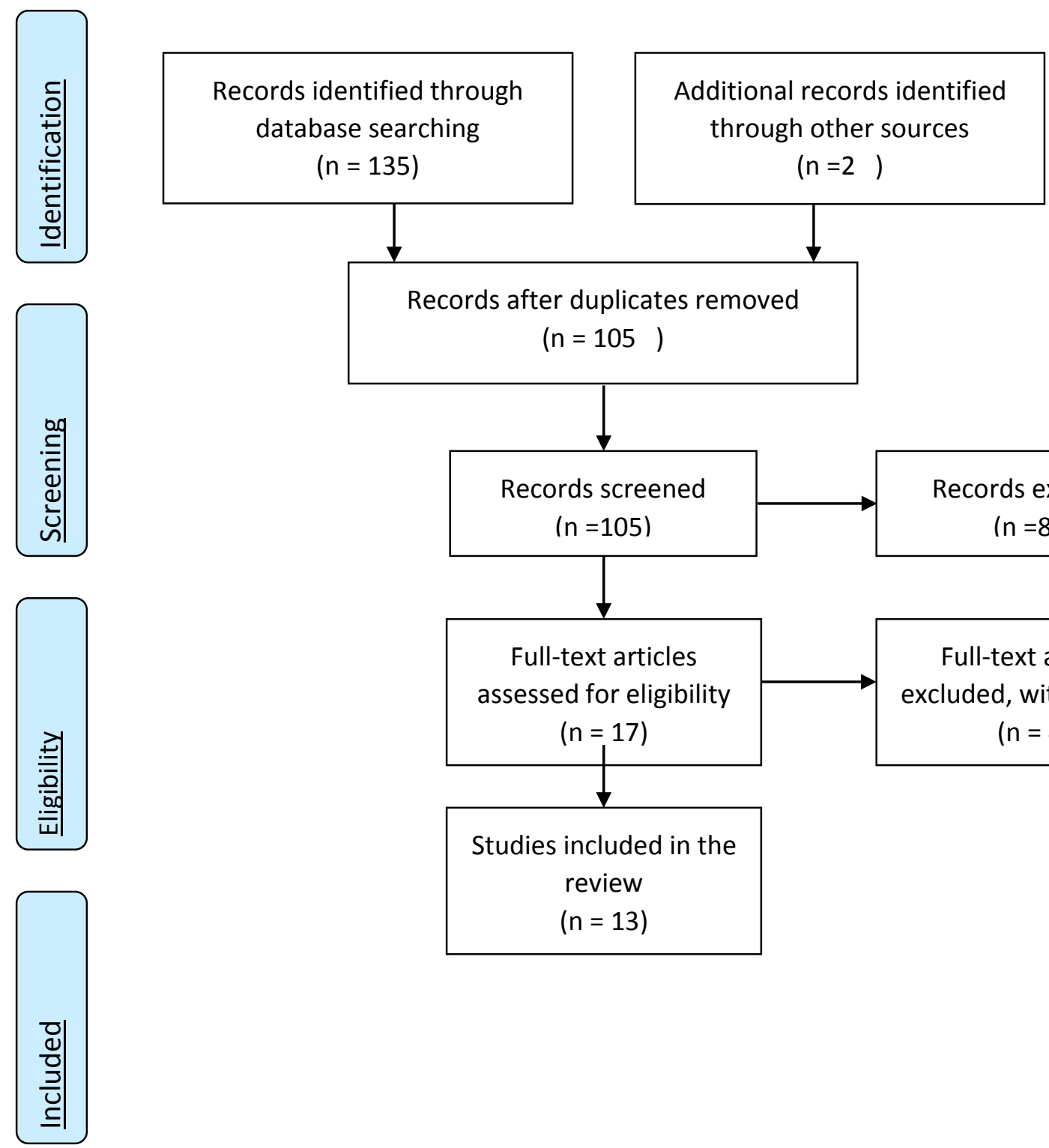

Records after duplicates removed

$(n=105)$
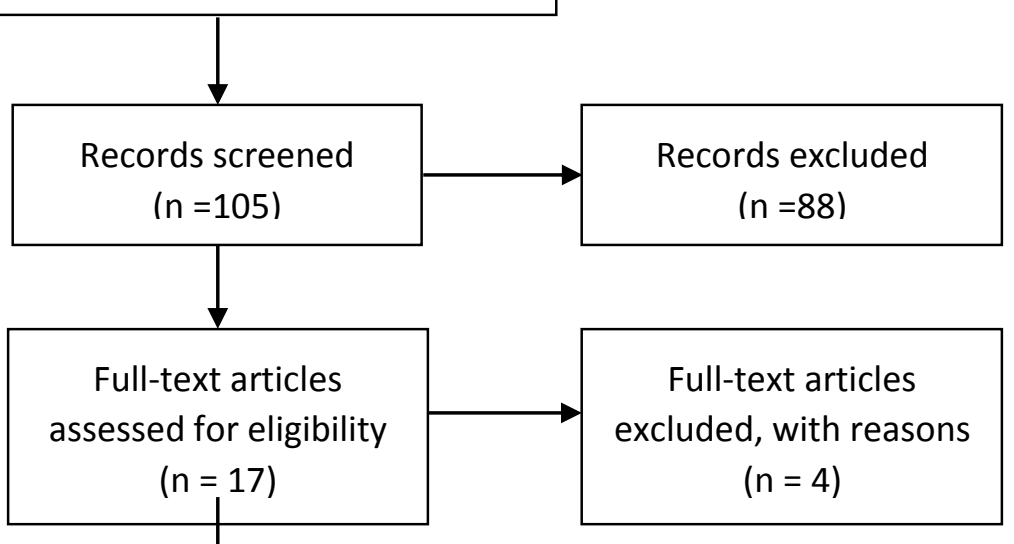

Studies included in the

review

$(n=13)$ 